\title{
Evaluation and space representation of the maximum surface runoff in watersheds
}

\begin{abstract}
In Cuba, regardless of the advances made in hydrological and hydraulic investigations related to floods, there are limitations with the detailed knowledge of the true maximum surface runoff or maximum flow that characterizes these phenomena in the season of intense rains, for which it is necessary to carry out complex hydrological study that, with the help of professional software and statistical techniques, help to determine and model spatially with certain reliability, the maximum water surface drained in watersheds. The general objective was pursued: To determine and represent spatially with the use of Geographic Information Systems (GIS) and hydrological methods, the runoff or maximum flow produced by the intense rains in a watershed, selecting to exemplify the watershed from the Magdalena River to the south east of the Santiago de Cuba municipality. As a result was obtained in the first instance, that it is feasible to apply this procedure to know in a preliminary way what maximum flow is available at any point of a main river or tributary. This approximation constitutes a significant advance for subsequent work in other watersheds of Cuba or internationally.
\end{abstract}

Keywords: watershed, runoff, spatial modelling, floods, procedure
Volume 5 Issue 6 - 2021

\author{
Alain Paneque Martínez,' Liber Galbán \\ Rodríguez, ${ }^{2}$ Rosana Caridad Ramírez \\ González \\ 'Faculty of Construction, Department of Hydraulic Engineering, \\ Universidad de Oriente, Santiago de Cuba, Cuba \\ ${ }^{2}$ Faculty of Construction, Department of Hydraulic Engineering, \\ Universidad de Oriente, Santiago de Cuba, Cuba \\ ${ }^{3}$ Faculty of Construction, Department of Hydraulic Engineering, \\ Universidad de Oriente, Santiago de Cuba, Cuba

\begin{abstract}
Correspondence: Alain Paneque Martínez, Faculty of Construction, Department of Hydraulic Engineering, Universidad de Oriente, Santiago de Cuba, Cuba, Email alain5@uo.edu.cu, liberg@uo.edu.cu, rosana.ramirez@uo.edu.cu
\end{abstract}

Received: November 20, 2021 | Published: December 08 2021

\section{Introduction}

Floods in watersheds are formed by different causes, although the most common are those that cause large surface runoff from the impact of heavy rains on them. A watershed is a land surface drained by a continuous, well - defined river system, whose waters pour another river system or other water objects with geosistemic characteristics own and, with limits generally determined by the main relief division; ${ }^{1}$ These occupy the space of the territhorium delimited by the dividing line of the waters that make water systems throughout the landmass of the planet, having a three - dimensional environment that integrates the interactions between coverage over the ground, the deep in the soil and around of this dividing line. These subsystems will vary according to the environment in which the basin is located and the level of intervention of the human factor (Figure 1).

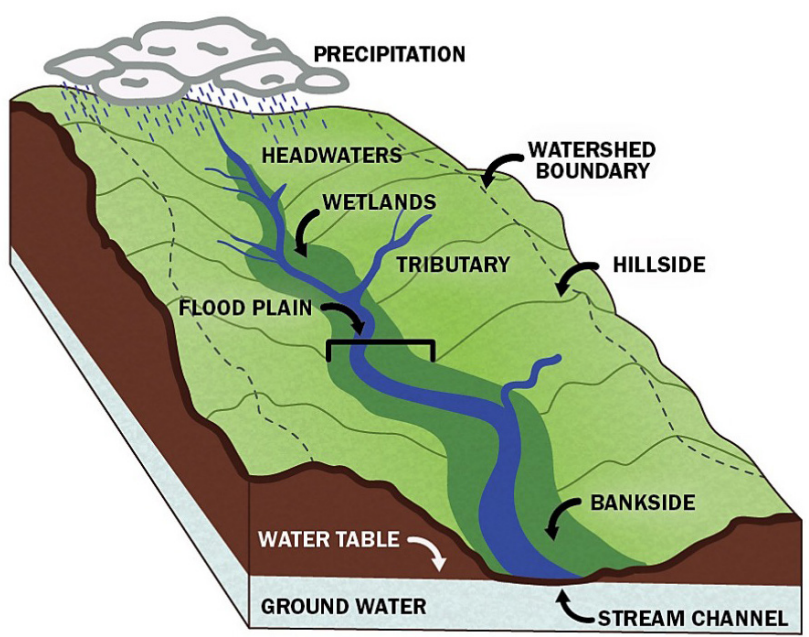

Figure I Elements of a watershed. http://littleconestoga.org/wp-content/ uploads/2018/08/watershed-0I.jpg.
Runoff or surface runoff is defined as that part of rain, melt water and / or irrigation water that does not infiltrate the soil, but instead flows into a river channel, moving over the surface. Runoff also includes water that reaches the riverbed relatively quickly just below the surface. Runoff is the most important element in predicting floods and floods in river valleys (Figure 2). The determination of the surface runoff of the basin is also essential for the realization of a reorganization and planning of the water resource in this area, as well as for the necessary calculations for the prevention of damages by the floods of the rivers and the floods to the different infrastructure and economic and social activities located in the basin; Hence, to determine its value it is necessary to link various sciences such as: Mathematics, Computing, Statistics, Hydrology, Geodesy, Geology and Cartography, etc.

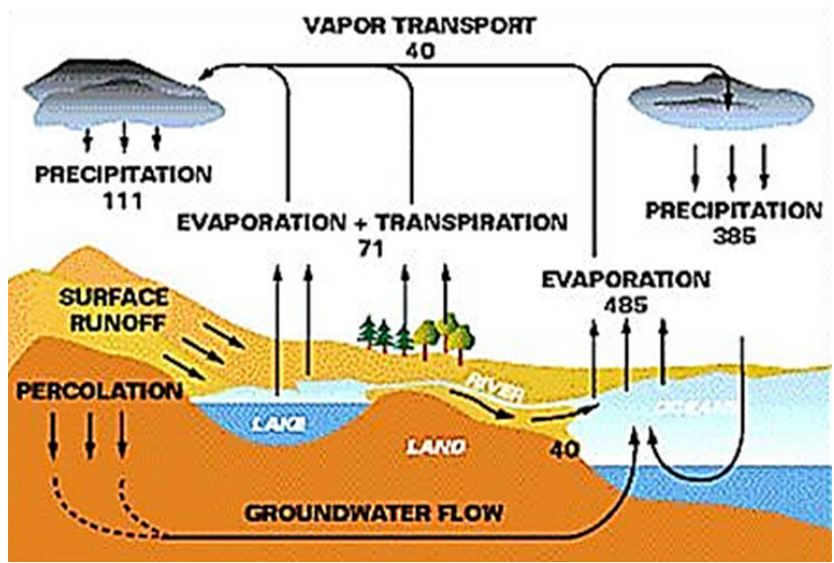

Figure 2 Scheme of surface runoff in riverbeds of watersheds. https:// slideplayer.com/slide//08/603I/.

According to the availability or lack of data, scientists who are dedicated to the study, prediction and modelling of floods have developed various methods, methodologies and instruments to 
determine these magnitude parameters, which undoubtedly constitute a powerful tool of prevention and reduction of disasters caused by the impact of floods. Broadly speaking, they can be grouped into 2 methodological approaches:

- Direct methods of estimating avenues, maximum expenses and height of floods.

- Indirect or empirical methods for estimating floods, maximum expenses and flood height.

At present there are a great variety of methods and empirical formulas for determining the maximum surface runoff or maximum flow that is experienced in a watershed, but the main problem is the correct application of these. The simplicity of these methods does not mean a lack of guarantee, since, in regions subjected to the same hydrological regime (regime guaranteed by conditions of homogeneity of the physical landscape and climate), the correlation between the surface of the basin and the maximum flow is obviously the most convenient. To make use of these formulas, it is necessary that the data on which they are based has been investigated, having to know the conditions under which it is intended to use them, the areas to which they are applied and understand the limitations that have been made by their authors. The recommendation is to apply at least 4 methods and then weigh the results.

The bibliographic consultation carried out confirms that both internationally and in the case of Cuban watersheds, in the majority the potential for average runoff of the same in their general closure of the coastal zone is known, and in several cases for closures of subbasins or micro-basins, above all due to the need for previous designs for the construction of dams and hydroelectric plants; as well as for its direct exploitation for the different consumptions demanded by society and the economy.

Particularly for the southern part of the Santiago de Cuba province, previously in 2017 the surface water potentials of the basins that are present in this region for coastal closures were determined (Table 1), confirming the need to detail the watershed above their values.

Table I Average precipitation and runoff by river watershed ${ }^{2}$

\begin{tabular}{lllllll}
\hline Watersheds & Average rain & Yo & Wo & Qo & Mo & Cv \\
\hline San Juan & 1190 & 220 & 30.36 & 0.96 & 7 & 0.65 \\
Sardinero & 1060 & 112 & 2.06 & 0.0165 & 3.5 & 0.75 \\
Justicí & 1100 & 116 & 0.16 & 0.005 & 3.57 & 0.75 \\
Carpintero & 1220 & 169 & 2.7 & 0.086 & 5.4 & 0.69 \\
Juraguá & 950 & 378 & 8.45 & 0.268 & 12 & 0.56 \\
Arenas & 1300 & 267 & 4.35 & 0.138 & 8.5 & 0.61 \\
Magdalena & 1320 & 279 & 9.23 & 0.29 & 8.9 & 0.61 \\
Duarte & 960 & 450 & 1.17 & 0.037 & 12 & 0.56 \\
Guinea & 900 & 434 & 1.13 & 0.036 & 13 & 0.55 \\
Cajobabo & 1000 & 613 & 2.21 & 0.007 & 14 & 0.54 \\
Uvero I & 940 & 1277 & 2.81 & 0.089 & 11 & 0.57 \\
Sigua & 940 & 404 & 18.95 & 0.601 & 13 & 0.55 \\
Baconao & 1330 & 284 & 70.43 & 2.23 & 9 & 0.61 \\
\hline
\end{tabular}

As can be seen, these studies are incomplete and subject to certain objectives, which does not satisfy the current need raised in the studies of danger, vulnerability and risks to floods that are developed in the country; reason for which the general objective was pursued: To determine and represent spatially with the use of Geographic Information Systems (GIS) and hydrological methods, the runoff or maximum flow produced by the intense rains in a watershed, selecting to exemplify the watershed from the Magdalena River to the south east of the Santiago de Cuba municipality. ${ }^{3-8}$

\section{Materials and methods}

At present, GIS worldwide have an application of great importance, in the case of hydrological studies. GIS tools such as HecRas, Arcview, ArcGIS, Emcom discover and Vertical Mapper (Mapinfo) and other specialized programs have applications to geographically represent hydrological parameters such as average rainfall, floods, among others. The GIS also include statistical and mathematical processing tools that allow, from certain parameters represented geographically and introducing the appropriate formulations, to obtain new desired values that are often calculated manually; thus allowing to automate these determinations. In the specific case of this research, a procedure is followed that is based on the use of indirect methods to determine the maximum surface runoff, made up of 4 steps in which a GIS is used to model the maximum surface runoff as described below.

\section{Step 1: Identification and general physical-geographical characterization of the watershed under study}

The physical and geomorphological characteristics of the basin depend on its geological structure, the relief of the earth's surface, the climate, the type of soil, the vegetation and, increasingly, the repercussions of human action on the environment of the basin. Next, reference is made to the main geographical physical characteristics of a basin that must be described in order to have as much information as possible about it. In this step, in addition, a general description of elements such as the location of the watershed, general pluviometric characterization, types of soils, rocks, population, among other data of interest that serve to locate to the specialists, is made. If there are previous studies, they should also be reflected in the reports. 
Step 2: Selection of the method or set of methods to determine the maximum surface runoff in the watershed, sub-basins and microbasins under study

The determination will be made by the methods described in the published international literature and its selection will depend on the conditions and basic information available in the investigation:

I. Rational method

II. Numerical curves method.

III. Classic Formulas.

IV. Hydrometheorological Formulas.

V. Isochron method.

VI. The expenditure hydrograph.

VII. Among others.

Step 3: Determination and spatial representation of the parameters that serve as the basis for the calculations of the maximum surface runoff or maximum flow

Specifically, most of the methods require parameters such as the following:

I. Determination of optimal closures

II. Determination of media rainfall in selected closures

III. Determination of the watershed area

IV. Perimeter length

V. Length of the main river and its tributaries

VI. Determination of mean slopes

VII. Soil roughness factor.

In the case of the GIS, once the digitized topographic map has been obtained, it is possible, through internal tools, to model the relief and obtain the Digital Elevation Model (DEM), which consecutively also allows obtaining the Digital Slope Model (DSM).

Today to delimit the watersheds, and the sub-basins and micro basins that compose them, the DEM is used, due to the ease with which the perimeter line can be drawn. Consecutively, the GIS, once the basin is delimited, mostly offer both the total delimited area and the length of the perimeter in an automated way, humanizing the work of the specialists. For the determination and spatial representation of the media rainfall in the selected closures, the different methods described in the literature can be used (Arithmetic Method, Isoietic method, Thiessen Polygon Method, among others.). In the same way, the data provided by the national isoetic map can be used, rectified with the values of rainfall stations near the basin in the process of analysis.

The identification and spatial representation of the soil roughness factor can be obtained from different basic informations, including: geology, digitized agricultural soil map, land use map and vegetation map; as well as those recognized in the methods themselves, such as the Manning roughness coefficient. The values are determined by combining the elements provided by each cartography, finally designating the value to each analysed area according to the proposals made by the different specialists.

Step 4: Spatial representation of the maximum surface runoff or maximum flow in the selected whatershed, sub-basins and microbasins with the use of a GIS

For this, the GIS have within their spatial processing tools some calculators, where the values of the original formulations are replaced by the names of the layers or maps obtained with the spatial representation of the basic parameters, and through the accept command the calculator processes and it issues a resulting map, which can be seen in detail at each point of the river or basin with the movement of the cursor.

\section{Results and discussion}

The watershed selected to apply the procedure was the Magdalena River, which is located at the East of the city of Santiago de Cuba in the municipality of the same name, in the area known as Gran Piedra National Park (Figure 3) (Table 2), where there are several watershed. The climate of the territory is tropical, although being located south of the Sierra de la Gran Piedra, dry conditions prevail. The average temperature is 26 degrees Celsius, being slightly lower in the higher areas. The factors that fundamentally determine the plant life of this territory, as well as of the entire Sierra de la Gran Piedra, are the relief and the distance to the sea. Due to the characteristics of the territory and the presence of the Sierra de la Gran Piedra, the hydrographic networks are small, and sometimes there are tiny basins that belong to intermittent rivers. The rivers are short, of little flow and torrential. In the rainy season they grow, and can destroy everything in their path, isolating various communities in the mountains. This locality is dominated by light red ferralitic, yellowish ferra-lithic, reddishbrown fecialitic, grayish-brown, carbonate humic, skeletal and alluvial soils. These soils are derived from perfithodiolitic rocks, porphyrites, granitoids and weathering, ferralitic crust. Its power is variable and is greater in the highest and most stable areas. The relief of the Magdalena River basin is mountainous, and the river forms an estuary at its mouth. It has a maximum height above 1000 meters, with an abrupt relief towards the mountain and softer towards the mouth Figure (4 \& 5).

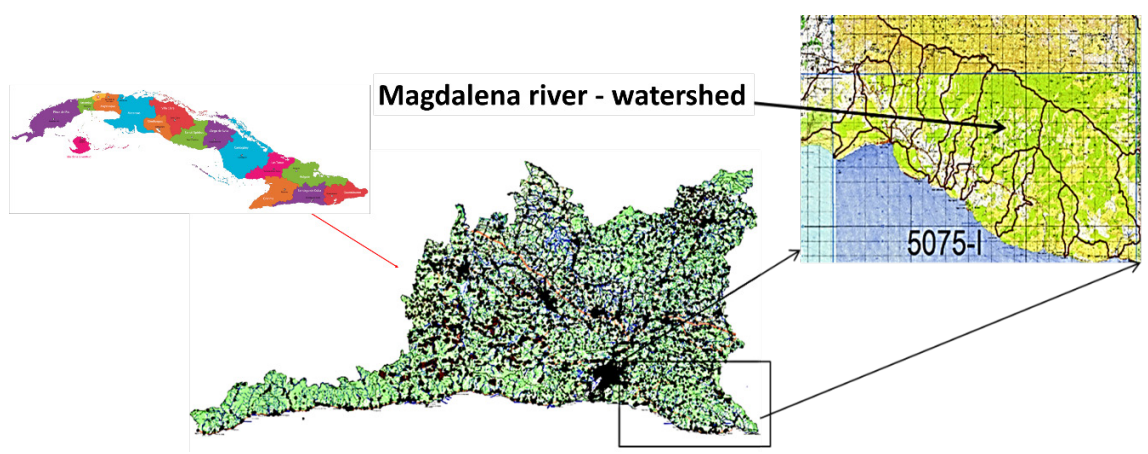

Figure 3 General location of the Magdalena river watershed in Santiago de Cuba province, Cuba. 


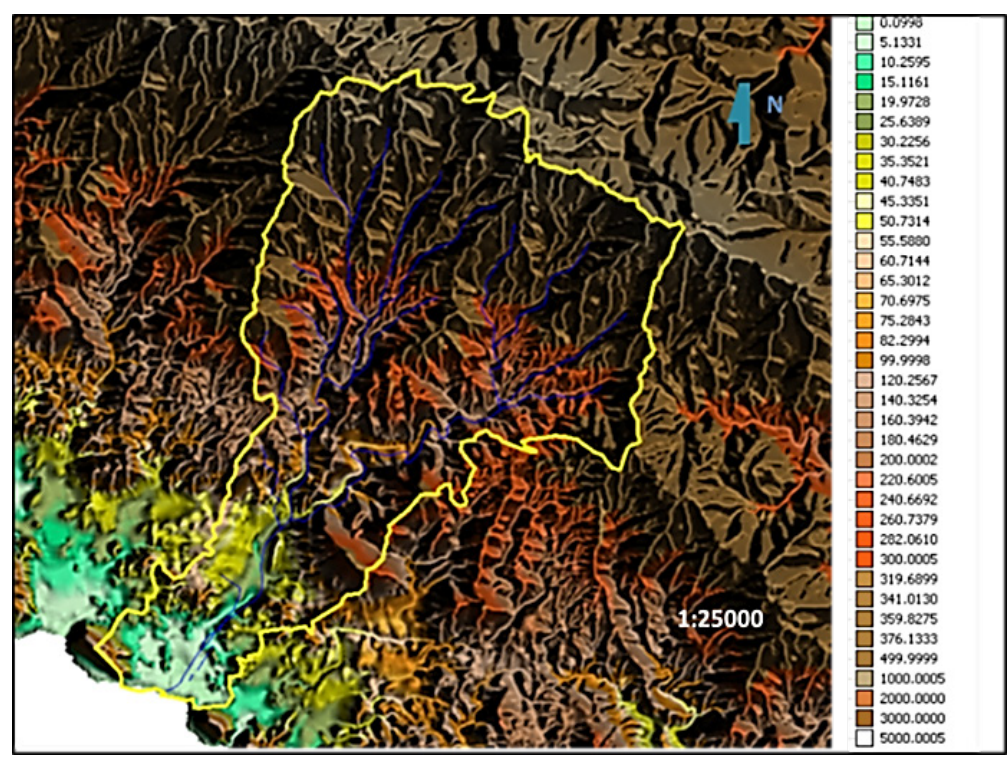

Figure 4 Digital elevation model (DEM) showing the delimitation of the Magdalena river basin and the predominant mountainous relief.
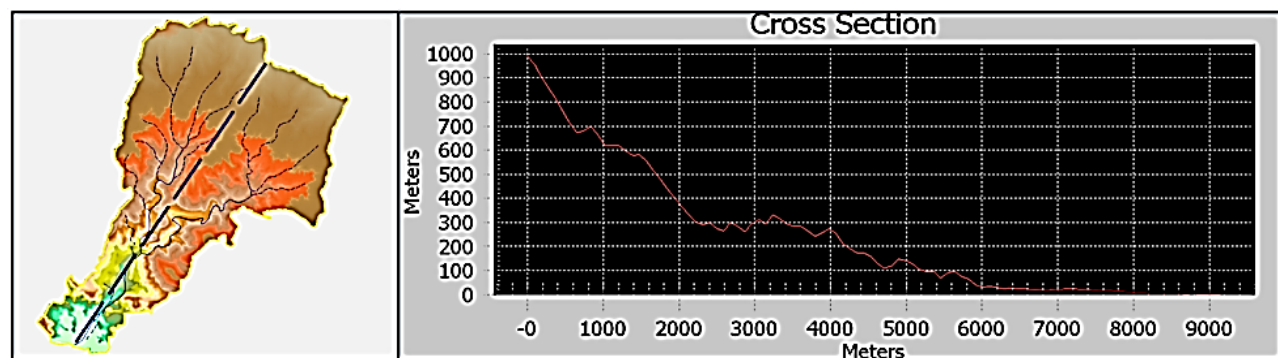

Figure 5 Longitudinal profile of the Magdalena river basin.

Table 2 General morphometric characteristics of the Magdalena river watershed

\begin{tabular}{|c|c|c|c|c|c|c|c|c|c|}
\hline Coordinates & Ac & $\mathrm{Hm}$ & $Y_{c}$ & $\mathbf{Y r}$ & Dd & Lr & HI & $\mathrm{H} 2$ & Clasif. \\
\hline NE & $\mathrm{Km}^{2}$ & m & $\begin{array}{l}\text { ol } \\
\text { oo }\end{array}$ & o/oo & $\mathrm{Km} / \mathbf{k m}^{2}$ & $\mathbf{K m}$ & m & m & \\
\hline 148.3624 .2 & 33.1 & 374 & 359 & 40.4 & 1.2 & 13.1 & 780 & 0 & $P$ \\
\hline \multicolumn{5}{|l|}{ Legend: } & \multicolumn{5}{|c|}{$\mathrm{H} 2$ - Level of the mouth of the river msnm } \\
\hline \multicolumn{5}{|c|}{ A - Area of the basin in $\mathrm{Km} 2$} & \multicolumn{5}{|c|}{ Yr-Slope of the river eo/oo } \\
\hline \multicolumn{5}{|c|}{ Hm- Mean height of the basin in $m$} & \multicolumn{5}{|c|}{ Yc - Average slope of the basin o/০o } \\
\hline \multicolumn{5}{|c|}{ Lr - River length in Km } & \multicolumn{5}{|c|}{ Dd - Drainage Density Km / Km 2} \\
\hline \multicolumn{5}{|c|}{$\mathrm{HI}$ - Level of the source of the river in masl } & \multicolumn{5}{|c|}{ The classification of the currents identifies whether they are permanent $(P)$ or intermittent $(I)$} \\
\hline
\end{tabular}

Source: Durand, 2017

\section{Results}

In the specific case of the ongoing investigation, which constitutes a first approximation to the determination of the maximum surface runoff with the use of a GIS, a simple method was chosen, the rational method as expressed below:

$$
Q p=166,67 * C^{*} I p^{*} A
$$

Where:

- C: Runoff coefficient (dimensionless).

- $\mathrm{A}=$ Area of the basin (ha)
- Ip: Intensity of rainfall, for the given probability.

- Qp: Expenditure or flow for the given probability.

For the runoff coefficient, specifically the one expressed in Table 3 is used, which regulates the values of the runoff coefficient (C) for watersheds not affected by urban growth, according to NC 48-26 (1984a) still in force in Cuba and they are recommended by Fundora (1989) and González. ${ }^{1}$

According to the selected closures, the basic parameters were calculated and then the behaviour of the area in different upstream closures was spatially modelled (Figure 6) (Table 4). 
Table 3 Runoff coefficient values (C) for watersheds not affected by urban growth

\begin{tabular}{|c|c|c|c|c|}
\hline \multirow[b]{2}{*}{ Ground cover type } & \multirow[b]{2}{*}{ Slope } & \multicolumn{2}{|l|}{ Soil type } & \multirow[b]{2}{*}{ Fine } \\
\hline & & Thick & Half & \\
\hline & & Sandy-silty & Sandy clay & Compact clays \\
\hline \multirow[t]{3}{*}{ Mountain } & $0-5$ & 0,10 & 0,30 & 0,40 \\
\hline & I0-May & 0,25 & 0,35 & 0,50 \\
\hline & $30-$ - ct & 0,30 & 0,50 & 0,60 \\
\hline \multirow[t]{3}{*}{ Natural Pastures } & $0-5$ & 0,10 & 0,30 & 0,40 \\
\hline & I0-May & 0,16 & 0,36 & 0,55 \\
\hline & $30-$ Oct & 0,22 & 0,42 & 0,60 \\
\hline \multirow[t]{3}{*}{ Cultivated soils } & $0-5$ & 0,30 & 0,50 & 0,60 \\
\hline & I0-May & 0,40 & 0,60 & 0,70 \\
\hline & $30-O c t$ & 0,52 & 0,72 & 0,82 \\
\hline
\end{tabular}

Table 4 Area, length and perimeter parameters calculated with the help of a GIS in the Magdalena river basin

\begin{tabular}{|c|c|c|c|c|c|}
\hline \multirow{2}{*}{$\begin{array}{l}\text { Magdalena watershed } \\
\text { Sub-basin I }\end{array}$} & \multicolumn{2}{|c|}{ Coordinates $X(\mathrm{~cm}) Y(\mathrm{~cm})$} & \multirow{2}{*}{$\begin{array}{l}\text { Areas (km2) } \\
14,79\end{array}$} & \multirow{2}{*}{$\begin{array}{l}\text { Perimeter (km) } \\
20,68\end{array}$} & \multirow{2}{*}{$\begin{array}{l}\text { Tributaries Length }(\mathrm{Km}) \\
6,885\end{array}$} \\
\hline & 627534,98 & 147470,66 & & & \\
\hline Sub-basin 2 & 628983,57 & $|4656|, 63$ & 14,82 & 22,18 & 7,991 \\
\hline Micro-basin I & 626379,52 & |4777|,85 & 2,205 & 6.896 & 2,085 \\
\hline Micro-basin 2 & 626985,57 & $|489| 2,5 \mid$ & 3,306 & 9,420 & 3,092 \\
\hline Micro-basin 3 & 628163,19 & $|4840|, 33$ & 6,510 & 15,24 & 3,943 \\
\hline Micro-basin & 629909,90 & 147743,53 & 5,599 & 10,73 & 3,165 \\
\hline Micro-basin 5 & $63047 I, 6 I$ & $|468| 2,30$ & 4,034 & $\mathrm{II}, 04$ & 2,327 \\
\hline Total basin & 627988,25 & $146 \mid 64,99$ & 34,88 & 34,42 & II,25 (main river) \\
\hline
\end{tabular}

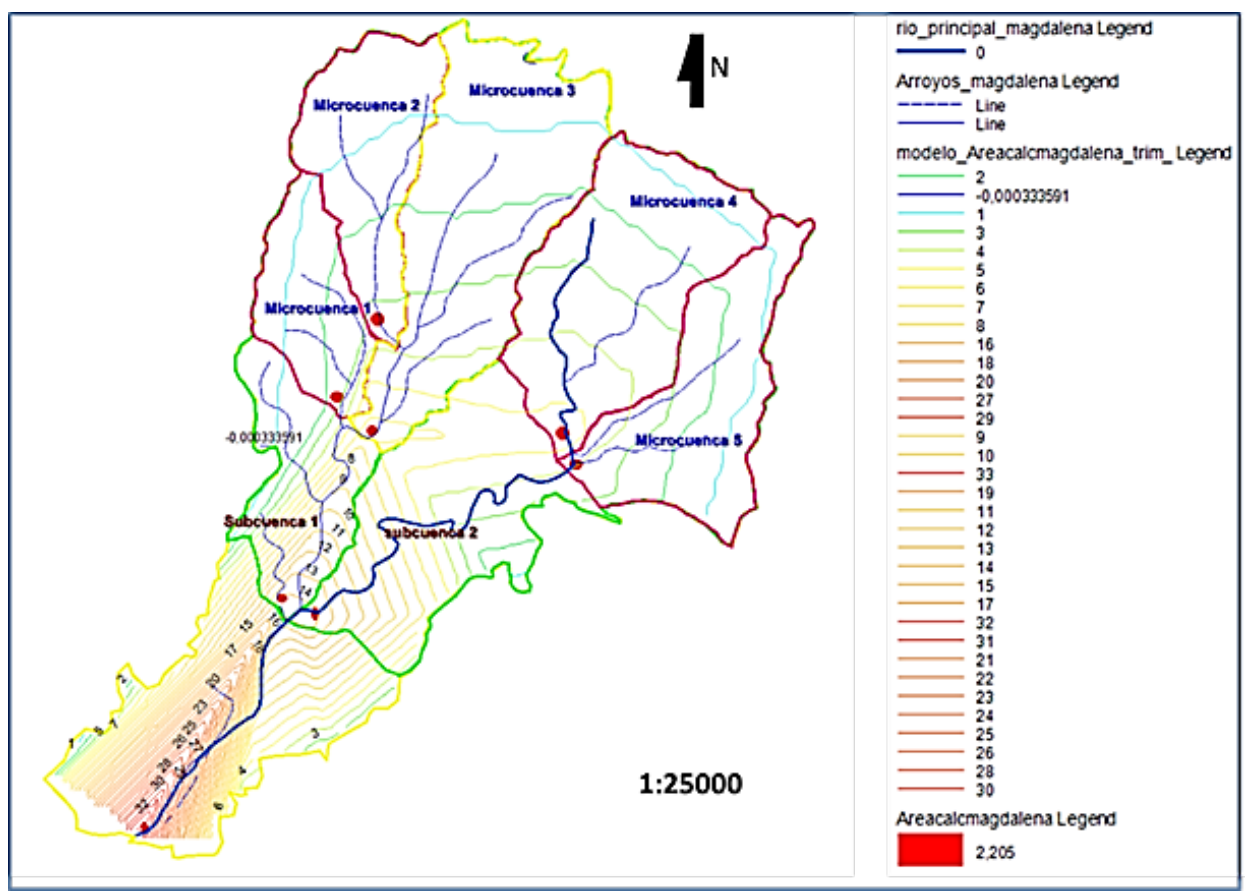

Figure 6 Isoline behaviour map of the areas determined for the Magdalena River watershed.

Citation: Martínez AP, Rodríguez LG, González RCR. Evaluation and space representation of the maximum surface runoff in watersheds. Int J Hydro. 202I;5(6):28I-287. DOI: I0.I5406/ijh.202I.05.00289 
In the study area, 8 rainfall stations were identified near the chosen watershed, although there are others whose records were taken into account for the elaboration of the provincial and national isoetic map, which were finally used in the research for the spatial modelling of the average rainfall annual (Figure 7). For the delimitation of the slopes and determination of the average slopes (Table 5), the slope model was obtained from the delimitation with the use of the Digital Elevation Model (DEM) at a scale of 1:25000, then the model of mean slopes for processing in the GIS in the same closures chosen above. For the proper selection of the runoff coefficient, the type of basin was taken into account, with the results of Table 6 , in correspondence with these values the runoff coefficient model of Figure 8 was obtained.

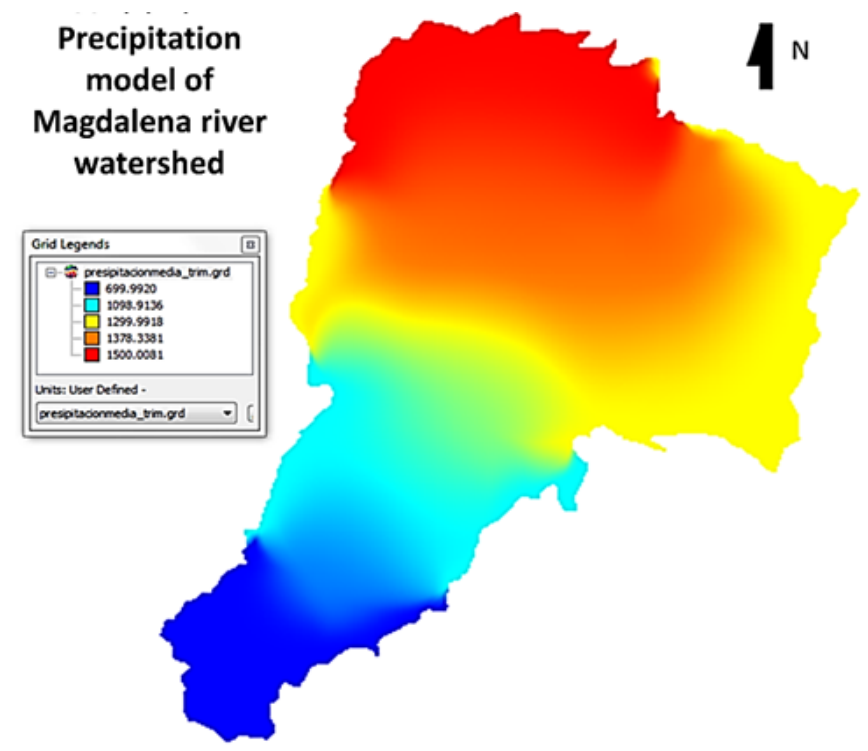

Figure 7 Precipitation model for the Magdalena River basin obtained with a GIS.

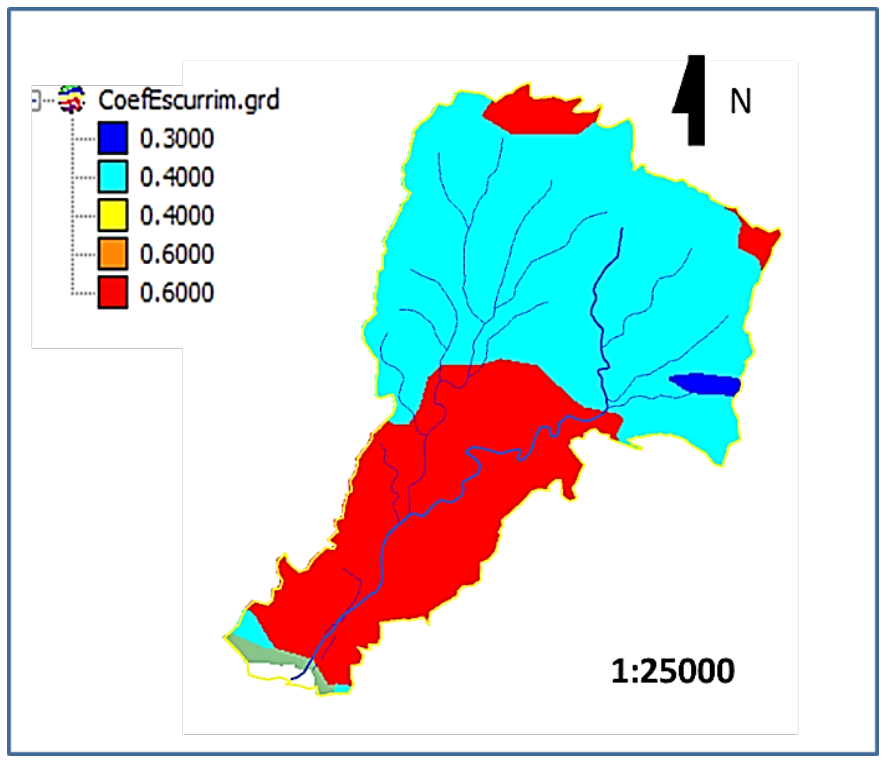

Figure 8 Spatial representation of the runoff coefficient with the use of a GIS.

\section{Discussion}

Once the primary models have been obtained in the GIS, the calculations of the maximum surface runoff are performed (Figure
9), allowing to know at any point in the watershed and the river the maximum surface runoff sheet or flow rate that later allows determining the maximum heights of river floods. Then the resulting models are obtained, delimited and taken to point values throughout the river's path (Figure 10). This approximation constitutes a significant advance for subsequent work in other watersheds of Santiago de Cuba and the country, allowing to know at any point of the river or stream an estimated value by indirect hydrological methods of the amount of water and the maximum flow that will run during the heavy rain season. On the other hand, it is clarified that the work carried out can be improved if more detailed cartographic scales are used, which would influence the obtaining of values closer to reality.

Table 5 Average slopes determined with the help of a GIS in the Magdalena river basin

\begin{tabular}{llll}
\hline $\begin{array}{l}\text { Magdalena } \\
\text { watershed }\end{array}$ & Slope (Máx.) & Slope (Min) & $\begin{array}{l}\text { Slope } \\
\text { (Media) }\end{array}$ \\
\hline Sub-basin I & 53,63 & 0,26 & 26,68 \\
Sub-basin 2 & 549,059 & 0,33 & 27,29 \\
Micro-basin I & 43,07 & 1,39 & 20,84 \\
Micro-basin 2 & 53,794 & 0,5018 & 26,65 \\
Micro-basin 3 & 549,067 & 0,0005 & 27,45 \\
Micro-basin 4 & 549,059 & 0,38 & 27,26 \\
Micro-basin 5 & 523,388 & 0,48 & 25,93 \\
Total & 54,906 & 0,0005 & 27,45 \\
\hline
\end{tabular}

Table 6 Behaviour of the runoff coefficient in the Magdalena river basin

\begin{tabular}{ll} 
Type of soil present & $\begin{array}{l}\text { Drainage } \\
\text { coefficien. }\end{array}$ \\
\hline
\end{tabular}

Porphyry-dioritic-quartz

Massive biodermal limestones, karstized with shells and corals, scarce intercalations of marl.

loamy sands

Andesites

Vulcanogenic and vulcanogenic-sedimentary rocks in different correlations and alternating combinations, highly variable

Granodiorites

Biohermic limestones with Acropora, marls, intercalations of calcareous clays and calcarenites.

Quartz - diorites 


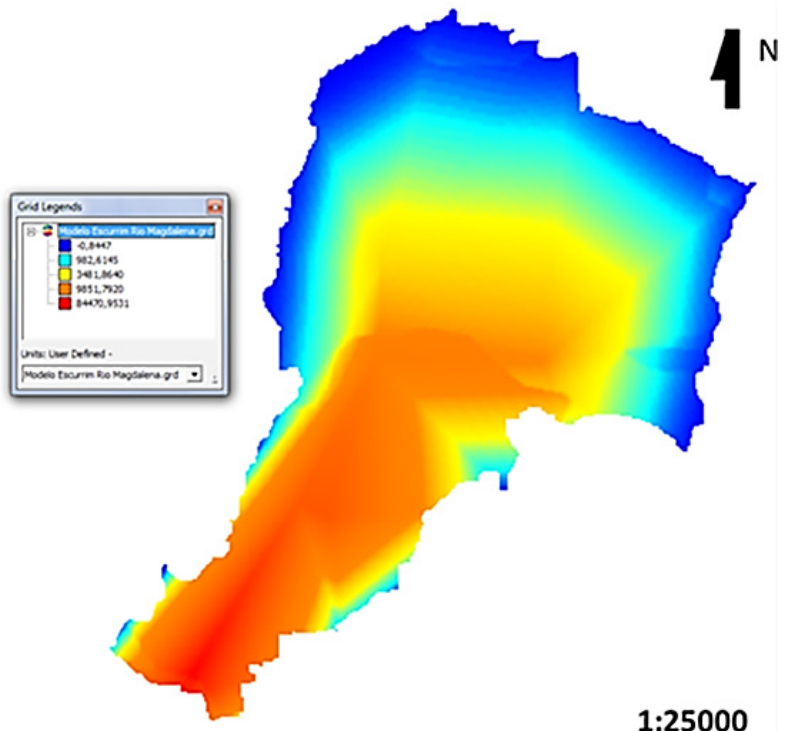

Figure 9 Image of the final model resulting from the maximum surface runoff obtained (above) and its delimitation around the main river and its tributaries (below).

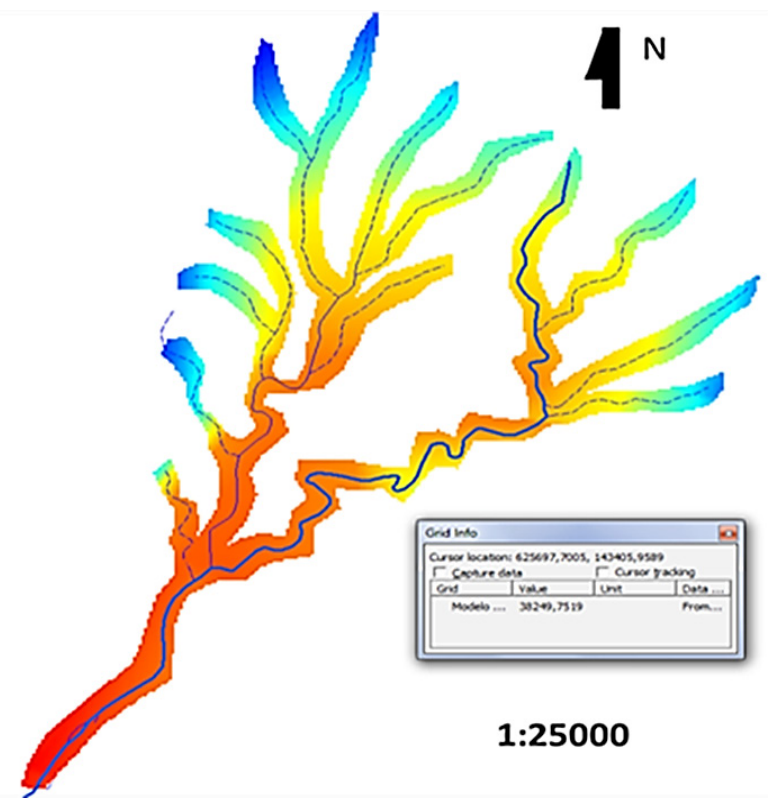

Figure 10 Model of the maximum surface runoff of the Magdalena River watershed taken to ranges (above) and its delimitation in the tributaries (below).

\section{Conclusion}

A methodological procedure was developed that allows guaranteeing the steps to be followed during the work for the modelling of the maximum runoff or detailed maximum surface flow in watersheds using a GIS, hydrological methods and statistical techniques (several of them inserted in GIS). The procedure follow 4 steps that characterizes the watershed, the primary models that are obtained, application of formulas for indirect runoff determination and the final runoff model that permit to observe its value in any point of the watershed.
The results obtained in the first instance show that it is feasible to apply this procedure to know in a preliminary way what maximum flow is available at any point of a main river or tributary of the selected hydrographic basin (Magdalena), spatially with the use of a GIS. This approximation constitutes a significant advance for subsequent work in other watersheds of Santiago de Cuba and the country, allowing to know at any point of the river or stream an estimated value by indirect hydrological methods of the amount of water and the maximum flow that will run during the heavy rain season.

\section{Recommendations}

I. The methodological procedure can be applied to determine and modelling the surface minimum runoff, medium runoff and maximum runoff in any watershed of the planet. The precision of the final model will depend of the initial cartographic data used by the specialists.

II. This kind of determinations can be more accurate if detailed cartographic scales are applied.

III. I is recommended that the specialists apply different formulations and, compare the final models results in order to select the one that more fits into their need.

\section{Acknowledgments}

The assessments made in this work correspond to a collaboration between the first phases of the project "Integrated monitoring and management of coastal ecosystems in the face of climate change in the eastern region of Cuba. (ECOS) ". 2021 - 2025. Sectorial Program " Higher education and sustainable development". Cuba; and the project "Strengthening professional training in hydraulic engineering for the eastern region of Cuba" (Sectorial Program " Higher education and sustainable development), both executed at the Universidad de Oriente in Santiago de Cuba, Cuba.

\section{References}

1. González SL. Extreme Hydrological Events. In: González Spíndola L., et al. Editors. Surface Hydrology for Engineers. CIH, ISPJAE, City of Havana. Cuba. 2007. p. 1-145.

2. Durand, Maria Teresa. Evaluation of the Water Potential of the Santiago de Cuba Province. Voluntad Hidráulica Magazine, March 2017, Havana, Cuba. 2017.

3. Aparicio MF. Fundamentals of surface hydrology. Limusa, Mexico. p. 303. 2007.

4. Campos Aranda DF. Processes of the Hydrological Cycle (Volume I and II). Editorial Universitaria Félix Varela, City of Havana. Cuba. 1992.

5. García Fernández, Jorge Mario, Gutiérrez Díaz. The management of hydrographic basins in Cuba. National Institute of Hydraulic Resources. National Council of Hydrographic Basins. Havana Cuba. 2015.

6. Piedra JIG. Methodological guide for the study of surface hydrological basins with Management projection, (unpublished). C. Havana, Cuba. 2007.

7. Rodríguez FF. Isoietic Map of the average rainfall of the Republic of Cuba, 1961-2000. Will Hydraulic Magazine. June 2006, Havana, Cuba. 2006.

8. Vich, Alberto Ismael Juan. "Inland waters, forms and processes". 1996. 